\title{
Comunicação
}

[Communication]

\section{Coleta de células progenitoras periféricas por aférese automatizada em equino: relato de procedimento}

\author{
[Viability of automated collection of peripheral blood progenitor cells \\ in a horse: report of procedure] \\ J.O. Bernardo' , P.B. Escodro ${ }^{2 *}$, M.K. Notomi' ${ }^{1}$, E.G. Roveri ${ }^{3}$, T. Gomes do Nascimento ${ }^{4}$ \\ ${ }^{1}$ Universidade Estadual Paulista "Júlio de Mesquita Filho" - São Paulo, SP \\ ${ }^{2}$ Universidade Federal de Alagoas - Maceió, AL \\ ${ }^{3}$ Universidade Estadual de Campinas - Campinas, SP \\ ${ }^{4}$ Escola de Enfermagem e Farmácia - Universidade Federal de Alagoas - Maceió, AL
}

Até a década passada, acreditava-se que as células-tronco eram encontradas apenas em embriões e tecidos de fetos (células embrionárias) (Romanov et al., 2003; Covas et al., 2003); medula óssea (Muraglia et al., 2000) e tecido adiposo (células mesenquimais) (Wickham et al., 2003); porém, estudos mais recentes mostram que estas também podem ser obtidas da corrente sanguínea, sendo chamadas de células progenitoras periféricas (CPP).

A utilização de células-tronco e biotecnologias regeneradoras vem sendo amplamente estudada na medicina veterinária, visando as recuperações tendíneas, ósseas e articulares. Atualmente, as técnicas utilizadas para obtenção de célulastronco em equinos é a coleta de células mesequimais, principalmente provenientes de tecido adiposo e medula óssea. Alguns autores afirmam que a medula óssea é a fonte mais rica para produção de células pluripotentes e utilização em terapias reconstrutivas de equinos e outras espécies (Koerner et al., 2006; Hegewald et al., 2004). No entanto, a coleta de CPP pode apresentar-se como método menos invasivo para obtenção dessas células, o que implicaria menor desconforto para o paciente e maior facilidade para aplicação clínica.

A automatização da coleta de CPP foi uma grande inovação na medicina e vem sendo amplamente utilizada há mais de 30 anos. Esse procedimento é realizado por meio da aférese, em que a coleta de sangue por uma veia periférica é realizada por um equipamento capaz de separar o grupo de células-tronco das demais células presentes no sangue (EBMT, 2013). A coleta de CPP em humanos já é uma realidade em centros de hemoterapia, e na Europa já substituem os transplantes de medula óssea convencionais (Corgozinho et al., 2012). Ainda, estudos de células-tronco isoladas de sangue periférico em cães e cobaias têm demonstrado grande capacidade de diferenciação em células mesenquimais para uso terapêutico (Koerner et al., 2006).

As vantagens da coleta de CPP por aférese são a possibilidade da realização da coleta em regime ambulatorial, não sendo necessária a anestesia do paciente; a menor taxa de morbidade e mortalidade; a menor contaminação de células tumorais no produto, além de representar um método menos invasivo e mais seguro quando comparado à coleta de células-tronco derivadas da medula óssea ou de tecido adiposo (Stem..., 2013; Koerner et al., 2006).

A viabilidade da utilização das CPP na espécie equina vem sendo estudada por alguns pesquisadores. Koerner et al. (2006) realizaram uma comparação de células progenitoras derivadas de sangue periférico com as células derivadas da medula óssea em equinos, por meio da coleta manual de CPP da veia jugular externa. Embora em seus resultados

Recebido em 29 de abril de 2016

Aceito em 31 de maio de 2016

*Autor para correspondência (corresponding author)

E-mail: pierre.escodro@vicosa.ufal.br 
tenham encontrado que a diferenciação das células provenientes da medula óssea é melhor do que das derivadas de sangue periférico, afirmam que este método demonstra vantagens em razão de a simplicidade de obtenção de células ser um método seguro e não produzir incômodos maiores aos doadores.

Com base nos estudos realizados por Escodro et al. (2013) para coleta automatizada de plasma em equinos, esta nota de pesquisa avaliou a possibilidade da coleta automatizada de CPP na espécie.

Este trabalho foi aprovado pelo Comitê de Ética em Pesquisa da Universidade Federal de Alagoas, pelo processo $\mathrm{n}^{\circ} 003111 / 2011-80$, para a realização de procedimentos de aférese automatizada em equinos.

Um equino, fêmea, da raça Quarto de Milha, dois anos, $385 \mathrm{~kg}$, foi encaminhada ao Ambulatório de Pesquisa e Extensão da Universidade de Federal de Alagoas com diagnóstico de osteoartrite interfalângica proximal do membro pélvico esquerdo. Por se tratar de uma enfermidade degenerativa, optou-se pela terapêutica com CPP para promover a regeneração articular, utilizando-se com ineditismo a coleta automatizada.

A aférese é capaz de separar, coletar e reinfundir as diversas frações do sangue simultaneamente (Stem..., 2013). O procedimento automatizado utiliza-se de um circuito plástico descartável e estéril acoplado ao equipamento de aférese. O sangue circula exclusivamente nesse circuito, não entrando em contato direto com o equipamento, quase deixando nulo o risco de contaminação (Razouk e Reiche, 2004).

A coleta de CPP foi executada com um separador celular de fluxo contínuo da Fresenius Kabi®, modelo AS104 (Fresenius-Kabi Ltda. Bad Homburg, Germany), acoplando-se o kit C4Y (Fresenius-Kabi Ltda. Bad Homburg, Germany), recomendado pelo fabricante para a realização de coleta de célula-tronco de sangue periférico e coleta de linfócitos (Stem..., 2013).

O procedimento foi realizado baseado na técnica padronizada por Escodro et al. (2013) para coleta automatizada de plasma em equinos. $O$ animal foi mantido em tronco de contenção, sem a necessidade de tranquilização (Fig. 1). Realizouse, então, a tricotomia, a antissepsia e a cateterização da veia jugular externa esquerda para retirada do sangue total, sendo denominada via de coleta e da veia jugular externa direita, denominada via de reinfusão, ambas com com cateter 14G (Nipro Medical Ltda. - Sorocaba, Brasil); em seguida, acoplou-se o kit $\mathrm{C} 4 \mathrm{Y}$ ao equipamento, seguindo as orientações do fabricante descritas no display.

Foram acopladas ao kit C4Y a solução de anticoagulante (citrato de sódio 20\% -Tate $£$ Lyle Brasil S/A, São Paulo, Brasil) e a solução fisiológica (cloreto de sódio 0,9\%, Fresenius Kabi Brasil Ltda. - Aquiraz, Ceará, Brasil) e, em seguida, foi selecionada a função prime, que preencheu os circuitos para evitar a entrada de ar no sistema. Como não é possível adequar os valores de peso e altura programados no equipamento, devido a este ser fabricado para humanos, foram alterados apenas os valores da concentração do anticoagulante (1:10) e hematócrito $(\mathrm{Ht})$ do animal $(32 \%)$, valores obtidos em procedimento realizado previamente à coleta de CPP, por meio do qual se coletou o sangue total do animal da veia jugular externa esquerda com a utilização do sistema Vacutainer (com agulha $25 \times 8 \mathrm{~mm}$ e tubos de vidro siliconizados para coleta a vácuo, com capacidade de $5 \mathrm{~mL}$, contendo anticoagulante EDTA - ácido etileno diamido tetracético a 15\%) (Becton Dickinson Vacutainer ${ }^{\circledR}$ - BD Diagnostics, Preanalytical Systems - São Paulo, Brasil) para a realização de um hemograma completo.

$\mathrm{O}$ equipamento funciona por meio da coleta do sangue total do animal doador, onde imediatamente são liberados volumes controlados de solução anticoagulante (citrato de sódio $20 \%$ ), que irá impedir a coagulação do sangue dentro do circuito. $\mathrm{O}$ sangue total com anticoagulante é encaminhado para a centrífuga, existente no equipamento, onde as células serão separadas conforme seu peso molecular. Dependendo do kit utilizado, será possível obter diferentes tipos de produtos. Na coleta de CPP, o concentrado de células progenitoras será encaminhado para uma bolsa de coleta, e o plasma e eritrócitos irão ser encaminhados para fora da centrífuga e se unir à solução fisiológica para ressuspensão desse concentrado; em seguida, irá retornar para o doador (Fig. 2). 


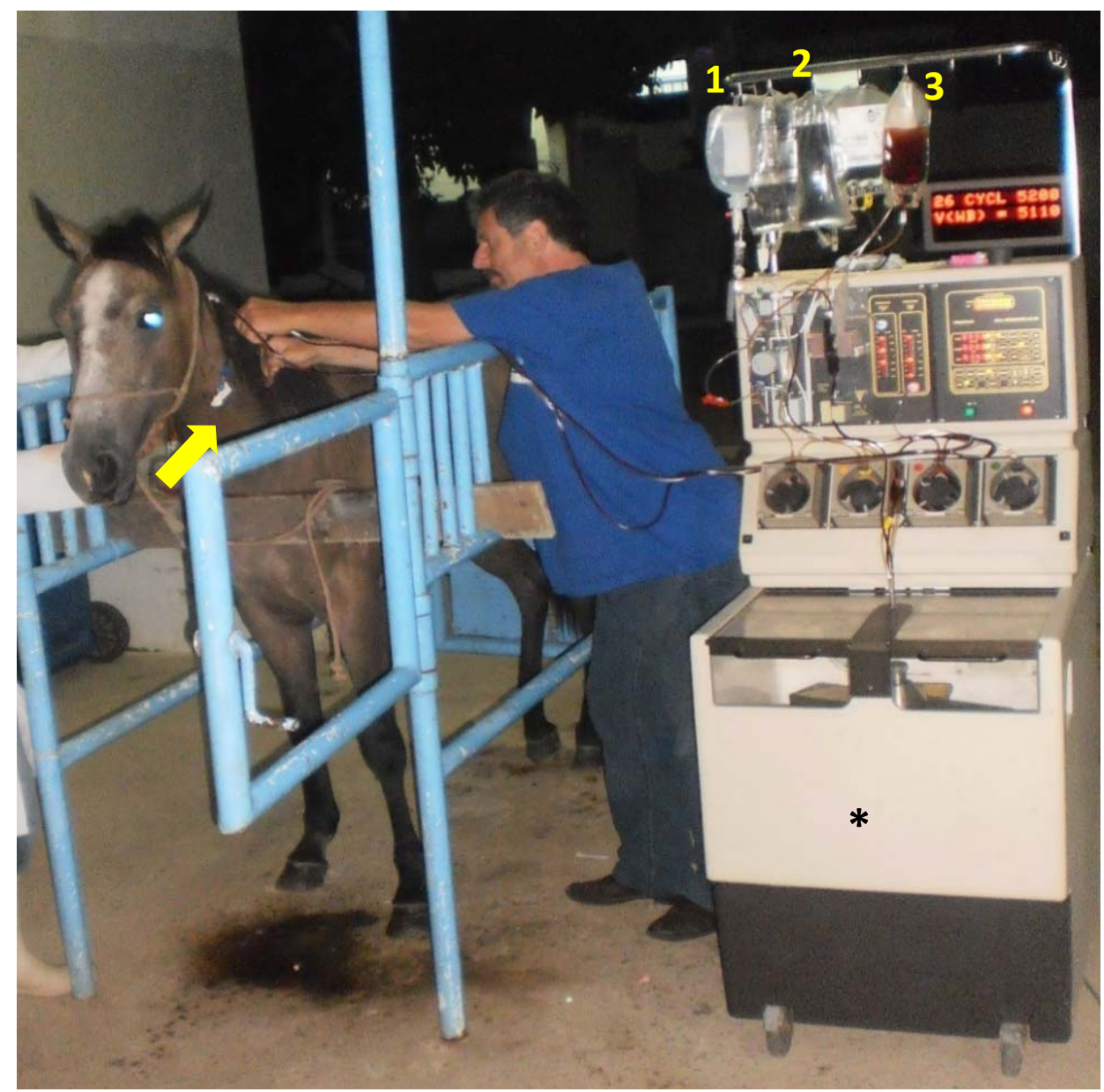

Figura 1. Animal em tronco de contenção para realização do procedimento de coleta de células progenitoras periféricas (CPP) por meio do equipamento de aférese Fresenius Kabi®, modelo AS104, acoplado com o kit CY4. Seta: via de coleta do sangue total mediante a cateterização da veia jugular esquerda; Asterisco 1: solução fisiológica (cloreto de sódio 0,9\%); 2: solução anticoagulante (citrato de sódio $20 \%$ ); 3 : bolsa de coleta de CPP; $(*)$ : compartimento onde se localiza a centrífuga que irá separar os componentes celulares.

O material coletado foi encaminhado para o Laboratório Clínico do Ambulatório de Pesquisa e Extensão da Universidade Federal de Alagoas, onde foi separado em alíquotas de $10 \mathrm{~mL}$ em capela de fluxo laminar (Filtracom - Valinhos, Brasil) e armazenado a $-18^{\circ} \mathrm{C}$ para posterior utilização.

A duração média do procedimento foi de $2 \mathrm{~h} 30$, realizando-se 26 ciclos, com processamento de $5054 \mathrm{~mL}$ de sangue total e obtenção de $351 \mathrm{~mL}$ de conteúdo de células progenitoras periféricas (Fig. 3). O tempo de coleta foi muito menor do que os relatos desse procedimento em humanos, que variam de quatro a seis horas de procedimento.

Não houve nenhuma intercorrência durante $o$ procedimento, diferindo da técnica de plasmaférese citada por Bernardo et al. (2012), em que os animais apresentaram flebite $\mathrm{e}$ obstrução do circuito por coagulação. Esse procedimento foi baseado em estudos dos mesmos pesquisadores (Escodro et al., 2013), e, após adequação e padronização da técnica da coleta de plasma, foi possível realizá-la com total exequibilidade. 


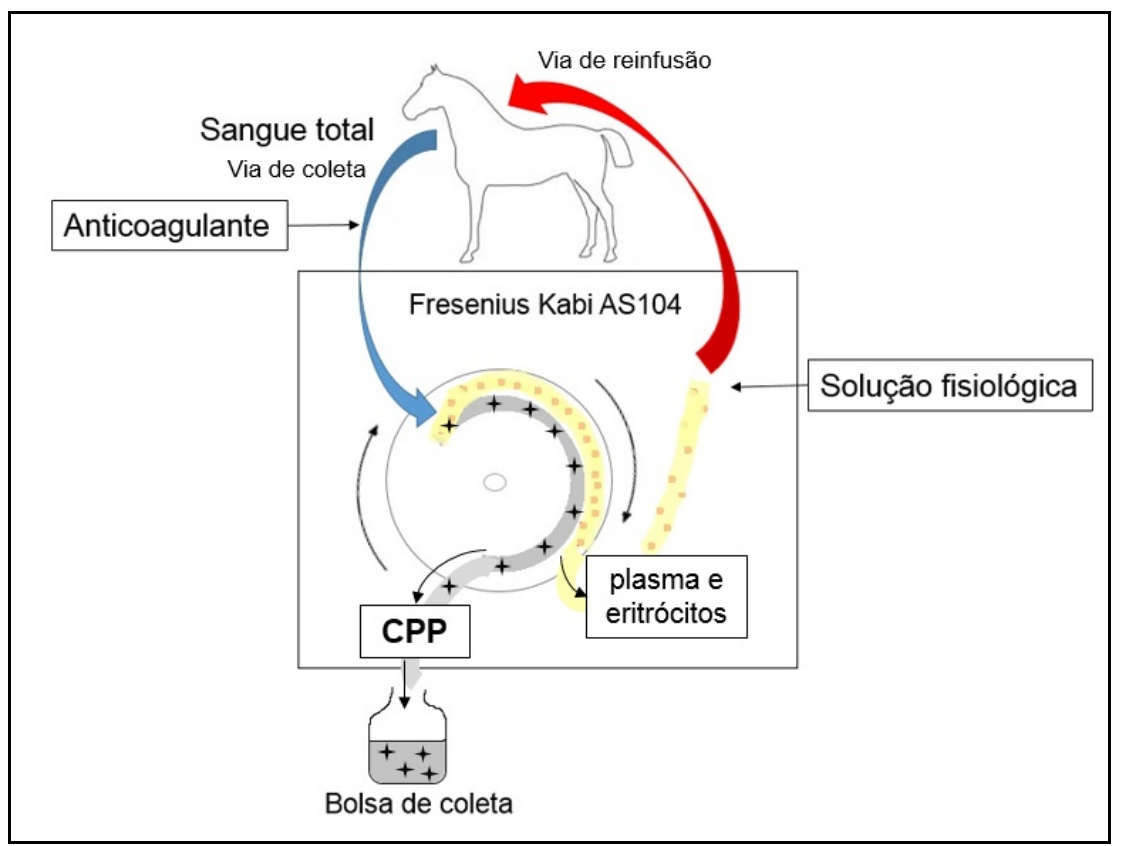

Figura 2. Esquema do funcionamento do equipamento de aférese Fresenius Kabi, modelo AS104. Após a coleta do sangue total do animal doador, imediatamente são liberados volumes controlados de solução anticoagulante (citrato de sódio 20\%), que irá impedir a coagulação do sangue dentro do circuito. O sangue total com anticoagulante é encaminhado para a centrífuga, existente no equipamento, onde as células serão separadas de acordo com o peso molecular de cada uma. O concentrado de células progenitoras será encaminhado para uma bolsa de coleta e o plasma e eritrócitos irão ser encaminhados para o circuito, onde será liberada solução fisiológica para ressuspensão desse concentrado; em seguida, irá retornar para o doador. Fonte: Adaptado de Feige et al. (2003).

A técnica automatizada de coleta de CPP mostrou-se viável para equinos, demonstrando, assim, ser inovadora técnica de coleta de células progenitoras com menor risco de contaminação e menores danos aos animais.

Porém, necessita-se de aperfeiçoamento de execução, objetivando alcançar maior eficiência, reduzir o tempo do procedimento e pesquisar sobre a diferenciação e eficiência das CPP para sua utilização clínica.

Palavras-chave: equino, célula-tronco, célula progenitora periférica

\begin{abstract}
The biotechnology used in tendon, bone and joint recoveries in Equine Medicine has improved in recent years. The most used are platelet rich plasma and stem cells from adipose tissue and bone marrow. However, recent studies have shown that stem cells can be found in the bloodstream, also named peripheral blood progenitor cells (CPP). This note aims at reporting the feasibility of automated collection of CPP in horses. The procedure was conducted in an equine, female, Quarter Horses, 2 years old, $385 \mathrm{~kg}$. The automated collection of CPP was conducted using apheresis equipment Fresenius- Kabi coupled to C4Y kit. The procedure lasted two hours and 30 minutes without complications, processing $5054 \mathrm{~mL}$ of whole blood and obtaining $351 \mathrm{~mL}$ of CPP. Upon completion of the collection, the content of CPP was separated into $10 \mathrm{ml}$ aliquots and immediately stored at $-18^{\circ} \mathrm{C}$. The automated technique proved to be feasible for horses, but needs improvement in order to achieve greater efficiency and reduce procedure time.
\end{abstract}

Keywords: horse, steam cells, peripheral blood progenitor cells 


\section{AGRADECIMENTOS}

À empresa Fresenius-Kabi, pelo auxílio concedido na disponibilização do equipamento de aférese. Ao $\mathrm{CNPq}$, pela concessão de bolsas de iniciação e produtividade em desenvolvimento tecnológico e extensão inovadora.

\section{REFERÊNCIAS}

BERNARDO, J.O.; ESCODRO, P.B.; ROVERI, E.G. et al. Automated plasmapheresis in horses: report of two cases. Ars Vet., v.28, p.148-152, 2012.

CORGOZINHO, M.M.; GOMES, J.R.A.A.; GARRAFA, V. Transplante de medula óssea no Brasil: dimensão bioética. Rev. Latinoam. Bioetica, v.12, p.36-45, 2012.

COVAS, D.T.; SIUFI, J.L.; SILVA, A.R. et al. Isolation and culture of umbilical vein mesenchymal stem cells. Braz. J. Med. Biol. Res., v.36, p.1179-1183, 2003.

ESCODRO, P.B.; BERNARDO, J.O.; ROVERI, E.G. et al. Standardization of automated plasmapheresis in horses. Arq. Bras. Med. Vet. Zootec., v.35, p.1049-1056, 2013.

FEIGE, K.; EHRAT, F.B.; KASTNER, S.B.R. et al. Automated plasmapheresis compared with other plasma collection methods in the horse. $J$. Med. Vet., v.50, p.185-189, 2003.

HEGEWALD, A.A.; RINGE, J.; BARTEL, J. et al. Hyaluronic acid and autologous synovial fluid induce chondrogenic differentiation of equine mesenchymal stem cells: a preliminary study. Tissue Cell, v.36, p.431-438, 2004.
KOERNER, J.; NESIC, D.; ROMERO, J.D. et al. Equine peripheral blood-derived progenitors in comparison to bone marrow-derived mesenchymal stem cells. Stem cells, v.24, p.1613-1619, 2006.

MURAGLIA, A.; CANCEDDA, R.; QUARTO, R. Clonal mesenchymal progenitors from human bone marrow differentiate in vitro according to a hierarchical model. J. Cell. Sci., v.113, p.1161$1166,2000$.

RAZOUK, F.H.; REICHE, E.M.V. Caracterização, produção e indicação clínica dos principais hemocomponentes. Rev. Bras. Hematol. Hemoter., v.26, p.126-134, 2004.

ROMANOV, Y.A.; SVINTSITSKAYA, V.A.; SMIRNOV, V.N. Searching for alternative sources of postnatal human mesenchymal stem cells: candidate MSC-like cells from umbilical cord. Stem cells, v.21, p.105-110, 2003.

STEM cell collection (apheresis), storage, and reinfusion. In: HAMEATOPOIETIC stem cell mobilization and apheresis: a practical guide for nurses and other allied health care professionals. [s.1.]: EBMT, 2013. Cap.13, p.13-18.

WICKHAM, M.Q.; ERICKSON, G.R.; GIMBLE, J.M. et al. Multipotent stromal cells derived from the infrapatellar fat pad of the knee. Clin. Orthop., v.412, p.196-212, 2003. 